\title{
SCHOLARLY COMMUNICATION
}

\section{Enhanced public access to NIH-funded research}

\section{Frequently asked questions}

\author{
by Prudence S. Adler
}

Note: The National Institutes of Health (NIH) recently announced a proposed plan to make the results of NIH-funded research publicly accessible through PubMed Central, the digital archive of the National Library of Medicine, within six months after publication in a peer reviewed journal. The proposal is available on the NIH Web site at grants1.nih.gov/grants/guide/notice- les /NOT-OD-04-064.html.

ACRL has been working actively in support of the NIH proposal in cooperation with SPARC, ARL and other major American library organizations, public interest groups (such as Creative Commons and Public Knowledge), and a large number of patient advocacy organizations. While the proposal has gained important backing, including endorsements by the National Academy of Sciences, 25 Nobel laureates, and the American Association of Universities, it has been strongly opposed by publishers.

The accompanying FAQ by ARL s Prudence Adler provides basic information about the proposal. Additional information is available on the Web site of the Alliance for Taxpayer Access, an umbrella coalition developed to lobby for implementation, at www.arl.org/ata/.
All ACRL members are encouraged to express support for the NIH proposal during the public comment period, which ends on November 16. Comments may be submitted on the NIH Web site at grants.nih.gov/grants /guide/public_access/add.htm or sent by email to PublicAccess@nih.gov.

ACRL members are also encouraged to write to their U.S. Senators and Representatives to express similar support. Ray English, chair, ACRL Scholarly Communications Committee,ray.english@oberlin.edu

1. What has NIH proposed concerning enhanced public access to NIH funded research? NIH proposes that research articles based on NIH funding, in whole or in part, be deposited in PubMed Central (PMC), a searchable public archive of biomedical literature in effect, NIH s institutional repository. These articles would become publicly available six months after publication in a peer-reviewed journal. Three of the goals of the proposal are to accelerate the pace of discovery, to provide additional capabilities to NIH in managing its research portfolio, and to enhance public access to biomedical literature. Congress has actively encouraged

\section{About the author}

Prudence S. Adler is associate executive director, Federal Relations and Information Policy, for the Association of Research Libraries, e-mail: prue@arl.org

(C) 2004 Prudence S. Adler 
NIH to explore new ways to better achieve these goals.

2. Does the NIH proposal mandate a restructuring of the scholarly communication system? The NIH proposal is neither a mandate from the federal government to the scienti c community concerning how and where to publish research articles nor does this proposed policy mandate changes to scienti c, technical, and medical (STM) publishing. The NIH proposal balances the public interest in access to federally funded research while maintaining the critical role of peer review and editorial processing by journal publishers. The NIH proposal is silent on where and when an author may publish. In fact, the proposal protects journal publishers by placing a six-month embargo on access to the deposited article. It does not mandate a shift from a subscriber-pays model to author-pays or other open access model. The NIH proposal is directed at enhancing public access to biomedical literature. It is not an open access proposal.

3. What has prompted NIH to propose enhancing access to biomedical information? It is NIH s mission to improve the health of all Americans through conducting and funding biomedical research. Timely and effective access to NIH-funded research by members of the scienti c community, teachers, health care providers, students, rst responders, and members of the public are key components to successfully achieving this mission. In addition, information technologies have had a profound impact on how science and research is conducted. This in turn has prompted many in the scienti $c$ community to promote new models of scholarly communication. Finally, sharp increases in journal subscription costs have led many, including the library community, to believe that the current system of scholarly publishing is neither a sustainable system nor one that adequately supports the research and education enterprise.

4. Who will benefit from enhanced access to biomedical information? Members of the scienti $\mathrm{c}$ and research communities, teachers, health care workers, rst responders, students, and members of the public will all bene $t$ from enhanced public access to biomedical literature. As demonstrated by the popularity of NIH s PubMed service (www.ncbi.nlm.nih.gov/entrez/query. fcgi), the demand for access to biomedical research goes far beyond the current readership for whom access is possible via subscriptions.

5. Will PMC be the only source for this biomedical information? PMC will be one of many sources for the biomedical literature archived in PMC. For example, as more institutions establish institutional repositories, it is anticipated that there will be multiple sites with a wide range of biomedical information, including comparable sites internationally. There is no requirement that PMC be the only source of this biomedical information.

6. Does PMC provide sufficient coverage to be a comprehensive and useful archive of biomedical information? In support of its mission, NIH has a long history of collecting, organizing, and disseminating biomedical literature. NIH and the National Library of Medicine (NLM) in particular have provided access to biomedical literature for well over 150 years. For example, beginning with the computerization of Index Medicus in 1964, the availability of MEDLARS Batch Mode in 1964, Medline in 1971, GenBank in 1983, and Clinical Trials and PMC in 2000, NIH and NLM have adopted and effectively used evolving information and communications technologies. These technologies permit NIH to provide more effective access to scienti c literature in new ways that re ect how the scienti c community engages in research and also allow the agency to better ful 11 its mission. Although it will not be the sole source, PMC will be a centralized resource for access and long-term archiving of articles generated through publicly funded biomedical research.

7. Does the NIH proposal impact intellectual property rights? No. NIH-funded research is currently copyrightable and will remain copyrightable under this plan. As 
before, copyright initially belongs to the author. If the author submits an article based on NIH-funded research to a journal that requests transfer of copyright, then the author is free to transfer copyright and the journal is free to acquire it. However, under terms of the grantee s agreement with $\mathrm{NIH}$, NIH must be given a royalty-free, non-exclusive, and irrevocable license for the Federal Government to reproduce, publish and otherwise use the material. The NIH proposal would simply exercise that right while in no way interfering with the right of the author to cede copyright to a publisher if he or she wishes to do so. The publisher (or author, if he or she retains copyright) will have all the usual rights as a copyright owner.

8. Does the NIH proposal interfere with the private, commercial marketplace? No. Currently, much of NIH s annual budget of approximately $\$ 28$ billion supports research funding at public and private universities, research laboratories, and other institutions. This is a signi cant investment in scienti $\mathrm{c}$ research that supports scienti c discovery and researchers around the country, many in publicly funded institutions. The NIH proposal is making available the results of publicly funded research. It does not interfere with intellectual property rights of the authors or publishers nor does it mandate in which journals researchers should publish. It does, however, contain provisions to help journal publishers preserve subscribers. Commercial and not-for-pro t journal publishers bene $t$ from this government-funded research by publishing articles generated by federal research dollars. Finally, many believe that there will be positive market effects on other industries due to the acceleration of research.

9. What is the anticipated impact on the scholarly publishing marketplace? The proposed plan balances the public $s$ interest in having access to NIH-funded research with the publishers interest in preserving their paid subscriber bases. There are a number of reasons why most libraries are likely to continue to subscribe to journals.

PMC would not release the public access edition of an article until six months after pub- lication in a peer-reviewed journal unless the journal itself consents to an earlier release.

PMC would distribute the version approved by a journals peer-review process but not necessarily the version polished and formatted by the journal.

Most journals publish more than NIHfunded research. This means that PMC would only provide access to a subset of the articles in a given issue of a given journal. In addition, many journals publish more than peer-reviewed research articles, including letters, editorials, opinion pieces, review articles, book reviews, news, and conference information. None of these would have to be deposited in PMC.

10. What has been the impact of some open access journals and open access archiving on the STM market?

Some journals report that delayed open access increases subscriptions. The increase seems to be a result of the heightened visibility, impact, and usage of the journals articles.

In physics, where nearly 100 percent of new articles are freely available in an open access archive, subscription-based journals continue to thrive.

The NIH plan essentially calls for the open-access archiving of refereed articles or post-prints after a six-month delay. Elsevier permits its authors to deposit their manuscripts in open-access archives, with no delay at all. Moreover, Elsevier allows open-access archiving of the nal version of the text, after both peer review and copy editing.

More than 180 subscription-based journals currently make their contents openly available after an embargo period. Although the impact of this on their subscription bases has not been publicly reported, one might assume that if the impact was negative, they would have discontinued the practice.

11. Does the NIH proposal have implications for other disciplines beyond biomedicine? The NIH proposal is limited to articles generated from NIH-funded research.

(continued on page 603) 
Dominique Turnbow in attendance. Here is what Turnbow had to say about it: Immersion was an unforgettable experience that inspired me to re ect upon my own teaching pedagogy and create a repertoire from which to build to improve my skills. The Immersion faculty are clearly experts in their eld, with a passion for passing on their knowledge. I would highly recommend all librarians with instruction responsibilities to attend the program.

("Enhanced public access ..." cont. from page 600)

To date, other federal agencies have not made investments in the technical infrastructure comparable to PMC. In part, this re ects the differing means by which disciplines share data and research results. As noted by the Council of the National Academy of Sciences, While we endorse this NIH initiative, we note that it addresses issues relevant speci cally to biomedical research, and that it may not be replicable for research supported by other agencies, or in disciplines with different funding levels or different modes of research communication (www4.nationalacademies.org/news. nsf/isbn/s09162004? OpenDocument).

12. Does the Information Quality Act apply to the NIH proposal? The Information Quality Act, enacted in December 2000, directed the Of ce of Management and Budget (OMB) to issue government-wide guidelines that provide policy and procedural guidance to Federal agencies for ensuring and maximizing the quality, objectivity, utility, and integ-

("Alternative assessment . . ." cont. from page 589)

Practical Assessment, Research \& Evaluation (PARE). A cornerstone of the late and much missed ERIC.AE site, PARE is still a very much alive and essential online peer reviewed journal for all areas of assessment. Readers interested in alternative assessment can nd here a resource for study in the areas of the use and development of scoring rubrics, performance assessment in the
With both the 2004 regional and national programs behind us, we now have a total of nine librarians who have participated in the Immersion experience. For those of you who have not had this opportunity, applications are now being accepted online at www.acrl. org (click Events \& Conferences then Upcoming Events ) for the National Immersion 05 Program to be held at Eckerd College, July 29 August 3, 2005. The deadline for application is December 6, 2004.

rity of information disseminated by Federal agencies (www.whitehouse.gov/omb/fedreg / nal_information_quality_guidelines.html).

The Information Quality Act is not applicable to the NIH proposal for two reasons. First, the OMB guidance does not apply to archived documents distributed by a federal agency. In fact, the guidelines speci cally state, OMB agrees that archival information disseminated by Federal agency libraries (for example, Internet distribution of published articles) should not be covered by these guidelines. And second, the guidelines do not apply to documents produced by grantees that do not represent agency views. As noted by $\mathrm{OMB}$, the agencies have not authored these document and ... are simply ensuring that the public can have quicker and easier access to materials.

\section{Note}

With my thanks for the contributions of Rick Johnson, SPARC director, and Peter Suber, www.earlham.edu/\%7Epeters/fos /nihfaq.htm.

classroom, and current assessment practice for the Web-based classroom environment. Access: http://pareonline.net/Home.htm.

TCRecord.org. A free registration gives access to many areas on this online journal site, which features a rich page on alternative assessment and includes multiple paths for involvement and investigation, including a discussion forum and a weekly e-mail newsletter. Access: http://www.tcrecord. org/default.asp. 